\title{
Promoting effect of polyaniline on Pd catalysts for the formic acid electrooxidation reaction
}

\author{
Xianbin Ma, Yuanyuan Feng *, Yang Li, Yunshi Han, Guoping Lu, Haifang Yang, Desheng Kong \\ Key Laboratory of Life-Organic Analysis, College of Chemistry and Chemical Engineering, Qufu Normal University, Qufu 273165, Shandong, China
}

\section{A R T I C L E I N F O}

Article history:

Received 4 January 2015

Accepted 14 April 2015

Published 20 July 2015

\section{Keywords:}

Palladium

Polyaniline

Electrocatalysis

Formic acid electrooxidation reaction

\begin{abstract}
A B S T R A C T
Pd-based nanomaterials have been considered as an effective catalyst for formic acid electrooxidation reaction (FAOR). Herein, we reported two types of polyaniline (PANI)-promoted Pd catalysts. One was an $n \mathrm{PANI} / \mathrm{Pd}$ electrocatalyst prepared by the electropolymerization of aniline and the electrodeposition of $\mathrm{Pd}$. The other was a $\mathrm{Pd} / \mathrm{C} / n \mathrm{PANI}$ catalyst prepared by the direct electropolymerization of aniline on a commercial Pd/C catalyst. The results show that PANI alone has no catalytic activity for FAOR; however, PANI can exhibit a significant promoting effect to Pd. The current densities of FAOR on the Pd catalysts with a PANI coating show a significant increase compared with that of the Pd reference catalyst without PANI as a promoter. The promoting effects of PANI are strongly dependent on the electropolymerization potential cycles $(n)$. The highest catalytic activities for FAOR of all the $n \mathrm{PANI} / \mathrm{Pd}$ and $\mathrm{Pd} / \mathrm{C} / n \mathrm{PANI}$ catalysts were those of 15PANI/Pd and $\mathrm{Pd} / \mathrm{C} / 20 \mathrm{PANI}$. The mass-specific activity (MSA) of Pd in 15PANI/Pd was 7.5 times that of the Pd catalyst, and the MSA and intrinsic activity of Pd/C/20PANI were 2.3 and 3.3 times that of the Pd/C catalyst, respectively. The enhanced performance of Pd catalysts is proposed as an electronic effect between Pd nanoparticles and PANI.
\end{abstract}

(C) 2015, Dalian Institute of Chemical Physics, Chinese Academy of Sciences. Published by Elsevier B.V. All rights reserved.

\section{Introduction}

The extensive use of fossil fuel has caused high levels environmental pollution, leading to climate change, and an energy crisis. Therefore, there is an urgent need for the development of new power sources. As a high-efficiency energy conversion device, fuel cells have a critical role in the energy utilization sector [1]. Proton exchange membrane fuel cells use hydrogen and small organic molecules, such as $\mathrm{CH}_{3} \mathrm{OH}$ and $\mathrm{HCOOH}$, as the anodic fuels and have attracted much attention [2,3]. Compared with hydrogen, small organic molecules have a higher energy density and are easily transported and stored. Their application is becoming more promising over the next decade [4-6]. Direct formic acid fuel cells (DFAFCs) with the electrooxidation of formic acid as the anodic reaction have advantages such as a higher theoretical open circuit potential, lower rate of fuel crossover, non-toxic, and non-flammable. They are expected to become commercialized fuel cells [7].

However, there are problems for the development of DFAFCs. For example, palladium and platinum catalysts are easily poisoned by intermediates, and the catalytic properties including activity and stability need further improvement. For these reasons, efficient promoters, such as second metals [8-10], nonmetals [11], and metal oxides [12,13], have been

\footnotetext{
* Corresponding author. Tel: +86-537-4458301; E-mail: yfeng@mail.tsinghua.edu.cn

This work is supported by the National Natural Science Foundation of China (21403125) and the Scientific Research Foundation for the Outstanding Young Scientist of Shandong Province (BS2011NJ009).

DOI: 10.1016/S1872-2067(15)60863-4 | http://www.sciencedirect.com/science/journal/18722067 | Chin. J. Catal., Vol. 36, No. 7, July 2015
} 
proposed to enhance the catalytic properties of Pt or Pd catalysts via synergetic effect (bifunctional mechanism) or electronic effect (change in the $\mathrm{Pt} / \mathrm{Pd}$ electronic structure). Conductive polymers have long been considered as an attractive support material and promoter of catalysts because of their high surface area, low resistance, and high stability. A number of studies on the synthesis, characterization, and properties of conducting polymer-supported catalysts have been reported [14]. The list of conducting polymers applied to Pt or Pd catalysts includes polyaniline (PANI) $[15,16]$, polypyrrole $[17,18]$, polyfuran [19], polythiophene [20], and polycarbazole [21]. Polycarbazole can weaken the adsorption strength of $\mathrm{CO}$ on catalysts and thus allows CO oxidation under lower potentials [21]. PANI has an important role in changing the electronic structure of Pt and increases the activity and stability of Pt toward oxygen reduction reaction [15].

In the present study, two types of PANI-promoted Pd samples are prepared as catalysts for the formic acid electrooxidation reaction (FAOR). $n$ PANI/Pd catalysts are prepared by the electropolymerization of aniline on the glassy carbon electrode and the electrodeposition of $\mathrm{Pd}$. The $\mathrm{Pd} / \mathrm{C} / n \mathrm{PANI}$ catalysts are prepared through the direct electropolymerization of aniline on a commercial $\mathrm{Pd} / \mathrm{C}$ catalyst. The catalytic properties of Pd for FAOR with and without PANI are compared to evaluate the efficiency of PANI as a promoter for Pd catalyzing FAOR.

\section{Experimental}

\subsection{Preparation of the $n P A N I / P d$ and $P d / C / n P A N I$ catalysts}

A glassy carbon electrode $(d=5 \mathrm{~mm})$ embedded in a Teflon holder was used as the working electrode. Prior to each use, the electrode was polished with 0.5 and $0.05 \mu \mathrm{m}$ alumina suspensions followed by washing ultrasonically with $\mathrm{HNO}_{3}(1: 1)$, ethanol, acetone, and deionized water, sequentially. The solution for the electropolymerization of PANI was $\mathrm{H}_{2} \mathrm{SO}_{4}(0.5 \mathrm{~mol} / \mathrm{L})$ and aniline (0.05 mol/L). PANI was obtained after different cycles of cyclic voltammetry (CV) in a potential range from -0.2 to $0.9 \mathrm{~V}$ at a scan rate of $50 \mathrm{mV} / \mathrm{s}$. The subsequent deposition of Pd nanoparticles (NPs) was obtained after 20 cycles of CV in $\mathrm{H}_{2} \mathrm{SO}_{4}(0.5 \mathrm{~mol} / \mathrm{L})$ and $\mathrm{K}_{2} \mathrm{PdCl}_{4}(1 \mathrm{mmol} / \mathrm{L})$, in a potential range from -0.2 to $0.6 \mathrm{~V}$ at a scan rate of $50 \mathrm{mV} / \mathrm{s}$. The catalysts obtained through the above processes were marked as $n \mathrm{PANI} / \mathrm{Pd}$, and $n$ refers to the number of $\mathrm{CV}$ cycles for the electropolymerization of PANI.

$\mathrm{Pd} / \mathrm{C}$ catalyst (20 wt\%) was purchased from Johnson Matthey Company. The Pd/C catalyst ink was prepared by sonicating a suspension of the carbon-supported catalyst (5.0 mg) in isopropanol $(1.0 \mathrm{~mL})$. A $10 \mu \mathrm{L}$ sample of the suspension was transferred onto the disk electrode and air-dried. The subsequent electropolymerization of PANI was obtained via the same method as that for $n \mathrm{PANI} / \mathrm{Pd}$. PANI was obtained after different cycles of $\mathrm{CV}$ in the potential range from -0.2 to $0.9 \mathrm{~V}$ at the scan rate of $50 \mathrm{mV} / \mathrm{s}$. The catalysts were marked as $\mathrm{Pd} / \mathrm{C} / \mathrm{nPANI}$.

Aniline was purified by vacuum distillation and stored under nitrogen gas. All other reagents were of analytical grade and used as received.

\subsection{Physicochemical characterization of the $n P A N I / P d$ and Pd/C/nPANI catalysts}

To characterize the morphology of the $n \mathrm{PANI} / \mathrm{Pd}$ samples, an ITO electrode was used as the working electrode for the deposition of PANI and Pd NPs. The morphology of the $n$ PANI/Pd samples was investigated by field-emission scanning electron microscopy (SEM; JSM 7401F, JEOL, Tokyo, Japan) at an operating voltage of $3.0 \mathrm{kV}$. The morphology was also investigated using a JEM-2100 transmission electron microscope (TEM; JEOL) operating at $120 \mathrm{kV}$. X-ray photoelectron spectroscopy (XPS) measurements were taken on a Thermo ESCALAB 250 instrument (Rochester, NY, USA) with Al $K_{\alpha}$ radiation $(h v=1486.6 \mathrm{eV})$. X-ray diffraction (XRD) patterns were collected on a MiniFlex 600 X-ray diffractometer (Rigaku Co. Ltd, Tokyo, Japan $)$ at a scan rate of $4^{\circ} / \min \left(15^{\circ}<2 \theta<80^{\circ}\right)$ and the wavelength of the incident radiation was $0.15406 \mathrm{~nm}(\mathrm{Cu}$ $K_{\alpha}$ ). To characterize the crystal structure of the Pd NPs, the electrodeposition of Pd was carried out on carbon paper electrode (TGP-090, Toray, Tokyo, Japan) instead of the glassy carbon electrode as previously reported [22]. The mass of Pd electrodeposited on each $n$ PANI/Pd electrode was determined by inductively coupled plasma atomic emission spectrometry (PerkinElmer Optima-4300DV Spectrometer, Norwalk, CT, USA).

\subsection{Electrochemical characterization}

Electrochemical measurements were carried out in a conventional three-electrode cell at $25{ }^{\circ} \mathrm{C}$ using a $\mathrm{CHI} 760 \mathrm{E}$ electrochemical workstation (Shanghai Chenhua Apparatus, Shanghai, China). A Pt foil $(1.0 \mathrm{~cm} \times 1.0 \mathrm{~cm})$ and a saturated calomel electrode (SCE) were used as the counter electrode and reference electrode, respectively. All potentials in this work are referred to the SCE. CV and chronoamperometry tests of FAOR were performed in $\mathrm{H}_{2} \mathrm{SO}_{4}(0.5 \mathrm{~mol} / \mathrm{L})$ and $\mathrm{HCOOH}(2.0 \mathrm{~mol} / \mathrm{L})$ solution. The chronoamperometry curves were tested under a constant potential of $0 \mathrm{~V}$ vs SCE.

\section{Results and discussion}

\subsection{Characterization of the $n P A N I / P d$ and $P d / C / n P A N I$ catalysts}

Fig. 1 shows the SEM and TEM images of the $n P A N I / P d$ and $\mathrm{Pd} / \mathrm{C} / n \mathrm{PANI}$ samples. The deposited Pd NPs were uniformly dispersed on the surface of the electrode (Fig. 1(a)), and the interwoven fibrous network structure of PANI was formed after electropolymerization (Fig. 1(b)). The fiber network is not densely packed, making the polymer film highly porous. The morphology of the electrode surface changed significantly after the deposition of Pd NPs on the PANI electrode (Fig. 1(c)-(f)). In all of the $n$ PANI/Pd samples, the Pd NPs were immobilized on the dendrites of PANI. The dendrites of PANI were decorated with highly dispersed Pd NPs, which created a close proximity between the NPs and PANI. Such an affinity is desirable for the composite $n \mathrm{PANI} / \mathrm{Pd}$ materials to show a fast electron 

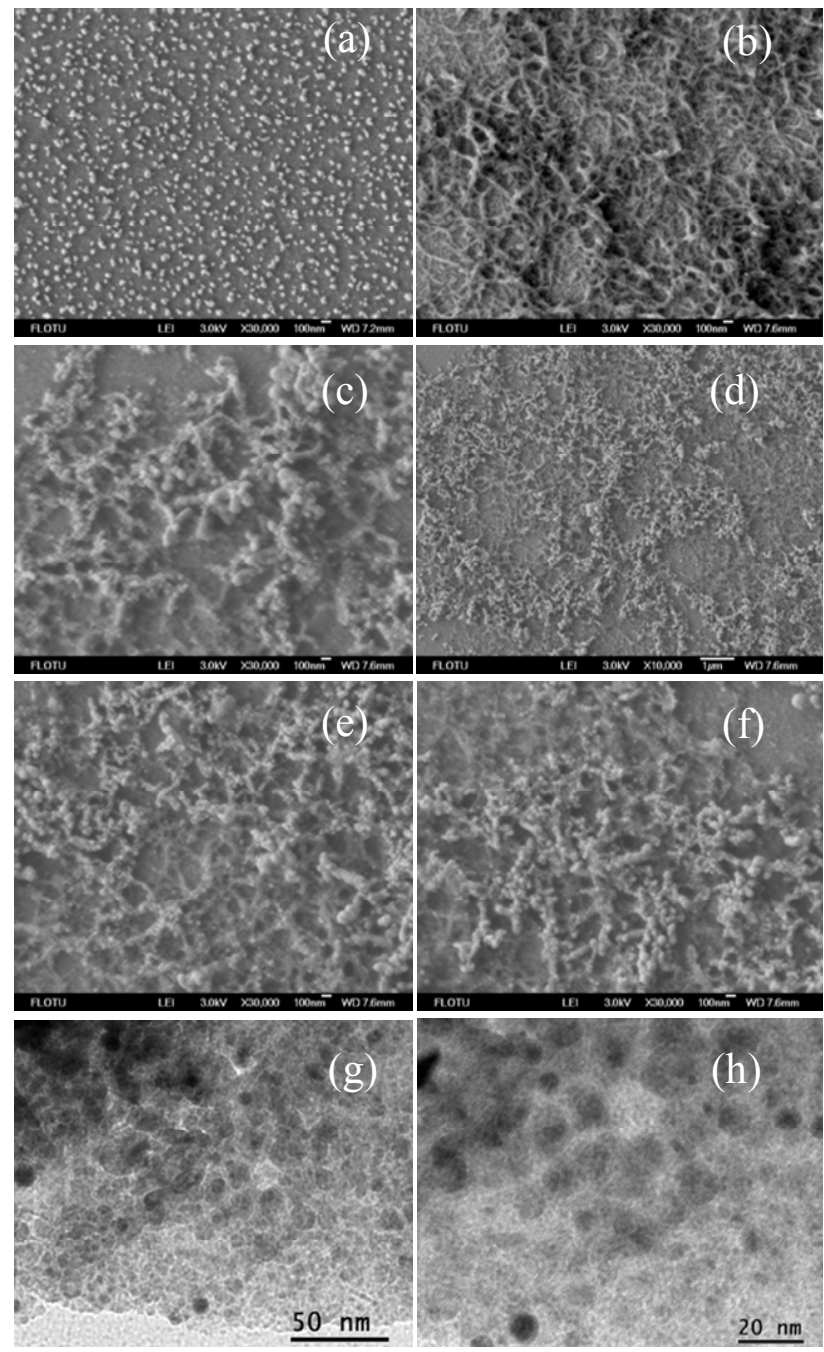

Fig. 1. Representative SEM images of the electrodeposited Pd NPs (a), electropolymerized PANI (b), 10PANI/Pd (c), 15PANI/Pd (d, e) and 20PANI/Pd (f) on ITO electrodes. (g) and (h) show the TEM images with different magnifications of the Pd/C/20PANI catalyst.

transfer rate and high conductivity. Additionally, increasing the electropolymerization cycles $(n)$ of PANI gradually increased

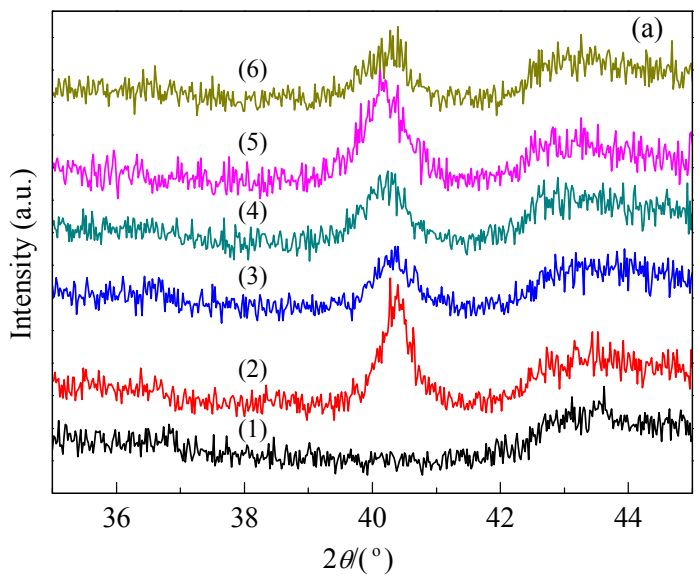

the thickness of the fiber network. Fig. 1(g) and (h) shows representative TEM images of the $\mathrm{Pd} / \mathrm{C} / 20 \mathrm{PANI}$ sample. After the deposition of PANI, the $\mathrm{Pd} / \mathrm{C}$ catalyst particles were covered with a PANI layer, and the boundary zones of the particles were unclear. Similarly, with the increase in electropolymerization cycles of PANI, the thickness of the layer gradually increased (results of other $\mathrm{Pd} / \mathrm{C} / n \mathrm{PANI}$ samples are not shown here). The thickness of the PANI layer may be crucial for the catalytic activities of Pd catalysts for FAOR.

To examine the crystal structure of the Pd-based catalysts, XRD measurements were carried out using a carbon paper electrode to replace the glassy carbon electrode. Because the intensity of the signals arising from the carbon paper is much higher than that from the Pd catalysts, we show a close-up of the XRD patterns in the range $2 \theta=35^{\circ}-45^{\circ}$. Fig. $2(\mathrm{a})$ and (b) shows the XRD patterns of the $n \mathrm{PANI} / \mathrm{Pd}$ and $\mathrm{Pd} / \mathrm{C} / n \mathrm{PANI}$ samples, respectively. The signals of the uncoated carbon paper (Fig. 2(a)(1)), the deposited Pd (Fig. 2(a)(2)) and Pd/C (Fig. 2(b)(1)) samples without PANI are also shown for comparison. The peak at $40.3^{\circ}$ was observed in all of the $n \mathrm{PANI} / \mathrm{Pd}$ and $\mathrm{Pd} / \mathrm{C} / n \mathrm{PANI}$ samples, and corresponds to the diffraction at the (111) planes of the face-centered cubic structure of metallic Pd (PDF \#46-1043) [23]. Other broad peaks associated with an overlap of peaks at $2 \theta=42.3^{\circ}$ and $44.4^{\circ}$ correspond to the (100) and (101) planes of the graphite carbon, respectively (PDF \#41-1487) [24], and these peaks showed the same positions as those of the uncoated carbon paper. There were no other diffraction peaks from the $n \mathrm{PANI} / \mathrm{Pd}$ and $\mathrm{Pd} / \mathrm{C} / n \mathrm{PANI}$ samples, suggesting that the PANI electropolymerized on the electrode was in an amorphous state.

Fig. 3 shows representative FTIR spectra of the 15PANI and 15PANI/Pd samples. Characteristic infrared peaks corresponding to the benzenoid and quinoid forms of the aromatic phenyl ring system at the fingerprint region between 800 and $1700 \mathrm{~cm}^{-1}$ were observed. Absorption bands at around 802 $\mathrm{cm}^{-1}$ were attributed to the bending of $\mathrm{C}-\mathrm{H}$ on the benzene ring out-of-plane [25]. The peaks at 1298, 1483, and $1566 \mathrm{~cm}^{-1}$ were for the stretching of aromatic- $\mathrm{N}$, stretching of $\mathrm{N}$-benzene ring $-\mathrm{N}$, and stretching of $\mathrm{N}=$ quinoid ring= $\mathrm{N}[26,27]$. Nearly all of the above mentioned functional groups on PANI were ob-

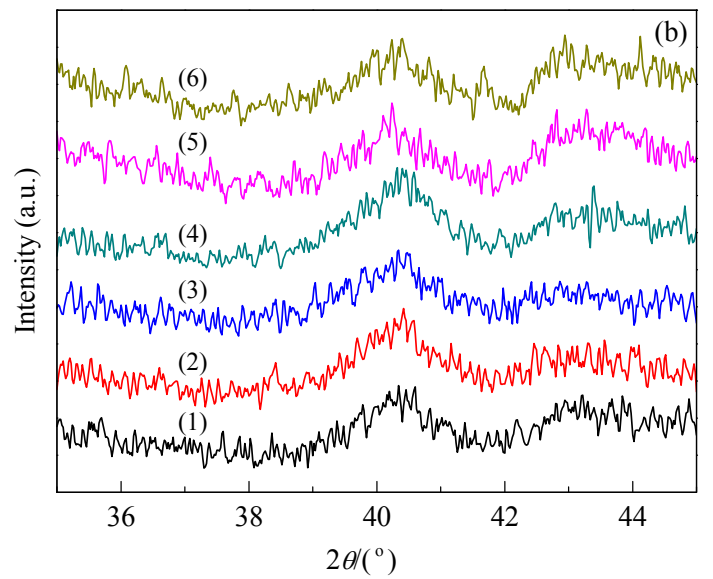

Fig. 2. XRD patterns of the $n$ PANI/Pd (a) and Pd/C/nPANI (b) samples. (a): (1) bare carbon; (2) deposited Pd; (3) $n=10$; (4) $n=15$; (5) $n=20$; (6) $n=$ 30. (b): (1) Pd/C; (2) $n=5$; (3) $n=10$; (4) $n=20$; (5) $n=30$; (6) $n=40$. 


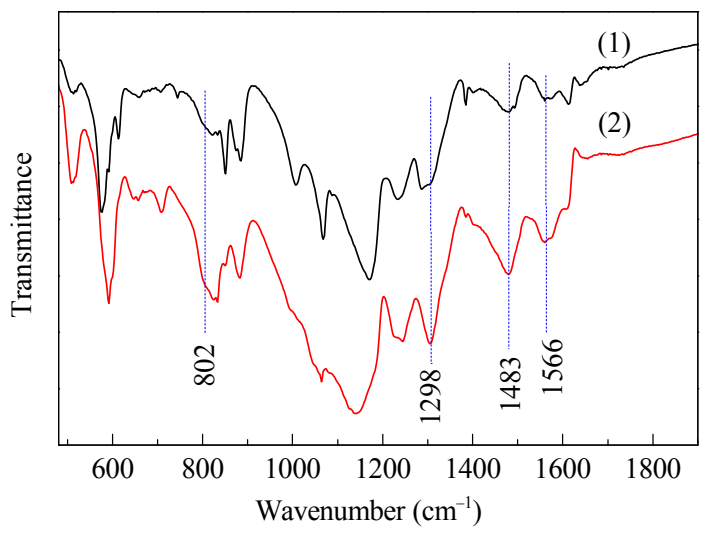

Fig. 3. FTIR spectra of the 15PANI (1) and 15PANI/Pd (2) samples.

served on $n \mathrm{PANI} / \mathrm{Pd}$, but with slight changes, which may be because of the charge-transfer between the Pd NPs and PANI.

\subsection{Electrosynthesis of the $n P A N I / P d$ catalysts on glassy carbon electrode}

The CV method was used to electropolymerize PANI because it is controllable. The thickness of PANI can be tuned through different numbers of potential cycling curves. Fig. 4(a) represents the successive $\mathrm{CV}$ curves during the course of the electropolymerization of aniline in $\mathrm{H}_{2} \mathrm{SO}_{4}(0.5 \mathrm{~mol} / \mathrm{L})$ and aniline $(0.05 \mathrm{~mol} / \mathrm{L})$ (30 cycles). The potential range was from -0.2 to $0.9 \mathrm{~V}$, and the scan rate was $50 \mathrm{mV} / \mathrm{s}$. The initial cycles did not show any redox signals in the whole potential range, and three couples of defined redox peaks were gradually observed with increasing potential cycling curves. The first peak at around $0.21 \mathrm{~V}$ was associated with the leucoemeraldine-emeraldine transition, the second at around $0.50 \mathrm{~V}$ corresponds to the oxidation of a head-to-tail dimer, and the third peak at the highest potential of $0.82 \mathrm{~V}$ was attributed to the conversion of emeraldine to pernigraniline. These CV curve profiles are similar to those reported in the literature [28,29]. Upon sequential cycles, the redox peaks gradually increased, suggesting the formation of an electroactive and conductive layer on the surface of the electrode.

After the PANI films were formed, Pd NPs were electrodeposited by $\mathrm{CV}$ from -0.20 to $0.60 \mathrm{~V}$ in $\mathrm{H}_{2} \mathrm{SO}_{4}(0.5 \mathrm{~mol} / \mathrm{L})$ and $\mathrm{K}_{2} \mathrm{PdCl}_{4}(1 \mathrm{mmol} / \mathrm{L})$ solution for 20 cycles at a scan rate of 50 $\mathrm{mV} / \mathrm{s}$. Fig. 4(b), (c), and (d) shows successive CV curves (20 cycles) during the electrosynthesis of Pd NPs on PANI formed after 10, 20, and 30 potential cycles, respectively. Compared with the redox peaks of PANI without the decoration of Pd NPs, those of PANI in $n$ PANI/Pd samples showed a lower intensity. For example, the current density of the 30PANI/Pd oxidation peak at $0.23 \mathrm{~V}$ was $0.58 \mathrm{~mA} / \mathrm{cm}^{2}$ (Fig. 4(d)), which was much lower than that of the 30PANI sample $\left(0.73 \mathrm{~mA} / \mathrm{cm}^{2}\right.$, Fig. $\left.4(\mathrm{a})\right)$.
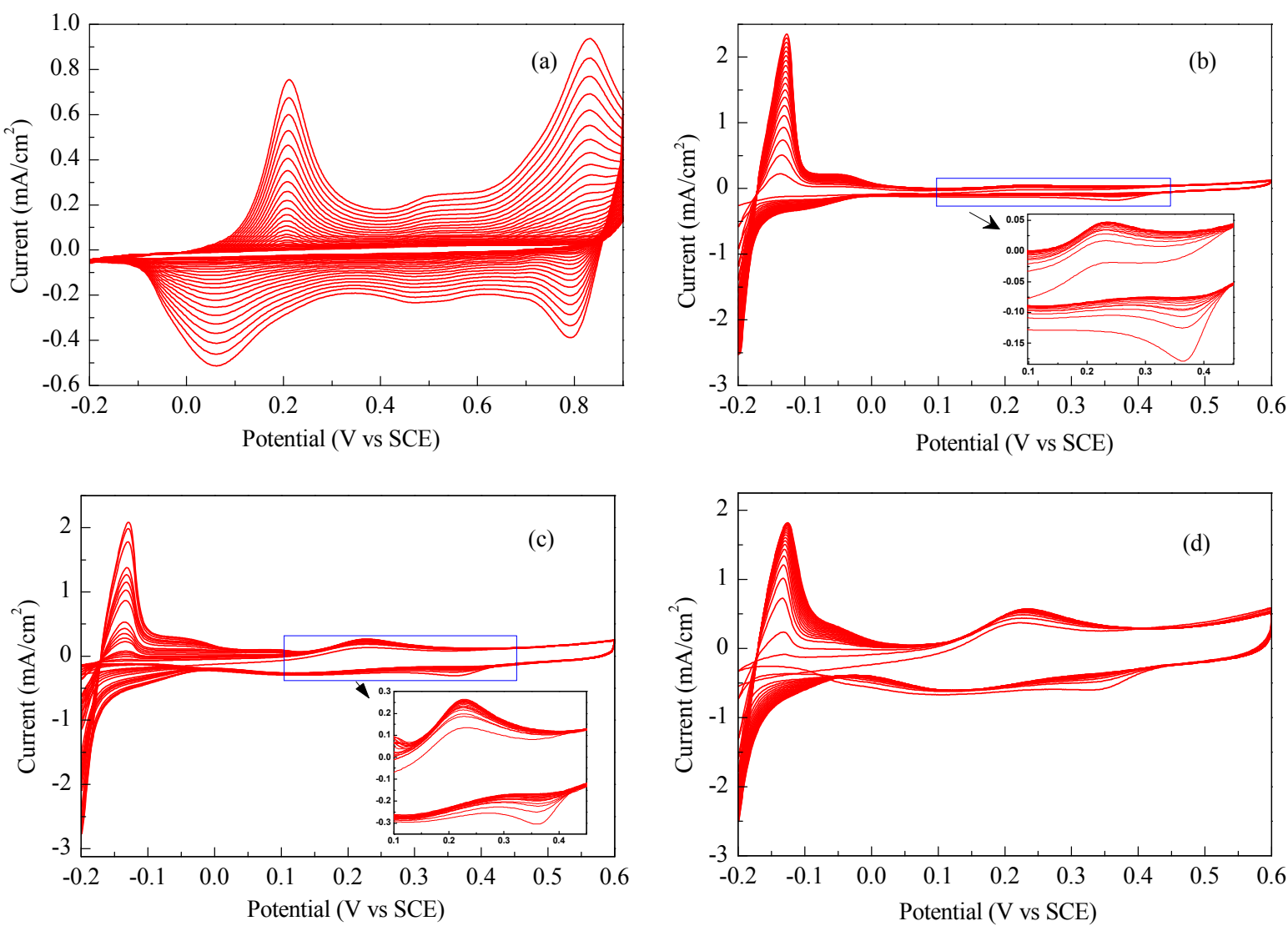

Fig. 4. (a) Successive 30 potential cycles in the course of electrochemical polymerization of aniline in $\mathrm{H}_{2} \mathrm{SO}_{4}(0.5 \mathrm{~mol} / \mathrm{L})+$ aniline $(0.05 \mathrm{~mol} / \mathrm{L})$ on glassy carbon electrode (scan rate: $50 \mathrm{mV} / \mathrm{s}$ ). (b), (c), and (d) show the successive 20 potential cycles in the course of deposition of Pd NPs on the PANI previously polymerized with 10,20 , and 30 potential cycles, respectively. The insets show the enlarged version of the corresponding CV curves (scan rate: $50 \mathrm{mV} / \mathrm{s}$ ). 
For all of the $n$ PANI/Pd samples, the peaks related to the hydrogen adsorption/desorption of $\mathrm{Pd}$ on the low potential side of CV were more pronounced with increasing cycle numbers, showing the increases in the Pd amount on the electrode and the high surface area of Pd NPs. In addition, the intensity of hydrogen adsorption/desorption peaks of the 20th CV curve in Fig. 4(b), (c), and (d) were different, even though the cycle numbers of Pd electrodeposition were the same (20 cycles). The intensity of the hydrogen adsorption/desorption peaks is strongly dependent on the thickness of the PANI substrate. With increasing the cycle numbers of PANI from 10 to 30, the intensity of hydrogen adsorption/desorption peaks gradually decreased. These results suggest that a thick PANI film leads to the Pd NPs embedding into the underlying PANI network and thus cannot be used for the catalysis. For the optimal efficiency of Pd NPs for catalytic reactions, the appropriate thickness of Pd film is necessary and crucial. The proximity between PANI and Pd NPs is important to enhance Pd utilization and may also be important for the catalytic activity of Pd.

\subsection{Electrochemical behavior of the $n P A N I / P d$ and $\mathrm{Pd} / \mathrm{C} / \mathrm{nPANI}$ catalysts}

Fig. 5(a) compares the cyclic voltammograms of the $n$ PANI/Pd samples in $\mathrm{N}_{2}$-saturated $\mathrm{H}_{2} \mathrm{SO}_{4}(0.5 \mathrm{~mol} / \mathrm{L})$ solution. Increasing the cycle numbers of PANI electropolymerization gradually increased the current density of the redox peaks associated with PANI. In addition, significant changes in the hydrogen adsorption/desorption peaks of the $n \mathrm{PANI} / \mathrm{Pd}$ samples were observed that were not seen with those of the Pd electrode. The hydrogen adsorption/desorption peak was very broad for the Pd electrode, which was similar to those reported for bulk Pd or Pd wire electrodes [16,30], whereas the profiles of the peaks for the $n \mathrm{PANI} / \mathrm{Pd}$ samples were well-defined. Because the exposed PANI surface would be inactive for hydrogen adsorption/desorption, the sharply increased peaks may be a consequence of the highly dispersed Pd NPs. The hydrogen atoms are adsorbed on the surface of Pd and intermixed with the inner layer of Pd NPs (absorption) [31,32]. The hydrogen region can then be divided into two parts: the most intensive peaks $(-0.13 \mathrm{~V})$ on the low potential side of the CV curve originating from the oxidation of adsorbed hydrogen; and the flat peaks at relatively high potentials $(-0.10$ to $0.05 \mathrm{~V})$ related to the oxidation of absorbed hydrogen on the surface of Pd [16].

Fig. 5(b) shows the CV curves of the $n \mathrm{PANI} / \mathrm{Pd}$ catalysts for FAOR in $\mathrm{H}_{2} \mathrm{SO}_{4}(0.5 \mathrm{~mol} / \mathrm{L})$ and $\mathrm{HCOOH}(2.0 \mathrm{~mol} / \mathrm{L})$ solution. The data of the reference Pd catalyst were also included for comparison. Besides the hydrogen region on the low potential side and the redox peaks corresponding to PANI, anodic peaks from the oxidation of formic acid on Pd catalysts at around 0.05 $\mathrm{V}$ were observed for all the $n \mathrm{PANI} / \mathrm{Pd}$ catalysts. The inset of Fig. 5(b) shows a close-up of the positive-going CV curves of formic acid oxidation. The current density of FAOR on the $n$ PANI/Pd catalysts showed a significant increase compared with that of the reference Pd catalyst. When the 10PANI film was used as the substrate, the current density of FAOR (at $0.05 \mathrm{~V}$ ) on 10PANI/Pd was $1.41 \mathrm{~mA} / \mathrm{cm}^{2}$, which was $\sim 5.2$ times that of the reference $\mathrm{Pd}$ catalyst $\left(0.27 \mathrm{~mA} / \mathrm{cm}^{2}\right)$. Increasing the cycle number to 15 (15PANI/Pd), the current density of FAOR increased to $1.70 \mathrm{~mA} / \mathrm{cm}^{2}$, which was $\sim 6.3$ times that of the $\mathrm{Pd}$ catalyst. When the cycle number of PANI was further increased to 20 and again to 30 , the current density of FAOR did not increase but decreased. There is a volcano-shaped dependence of the catalytic activity of Pd for FAOR on the cycle numbers of PANI electropolymerization. Because the mass of Pd on each $n$ PANI/Pd electrode was slightly different, the mass-specific activity (MSA) was appropriate for comparing catalytic activities. The data are listed in Table 1 . The highest catalytic activity of $\mathrm{Pd}$ in the $n \mathrm{PANI} / \mathrm{Pd}$ catalysts was that of 15PANI/Pd, the MSA was $0.209 \mathrm{~A} / \mathrm{mg}$, which is 7.5 times that of the Pd catalyst $(0.028 \mathrm{~A} / \mathrm{mg})$. This result may be because of the proximity between the deposited Pd NPs and PANI. Because PANI is inactive for the oxidation of formic acid, the enhanced catalytic properties may arise from a promoting effect of PANI [16].

To further evaluate the promoting effects of PANI on Pd, a commercial Pd/C catalyst was used as the substrate for PANI coating (denoted as Pd/C/nPANI). Fig. 6(a) shows 20 cycles of electrochemical polymerization of aniline on the $\mathrm{Pd} / \mathrm{C}$ catalyst in a solution of $\mathrm{H}_{2} \mathrm{SO}_{4}(0.5 \mathrm{~mol} / \mathrm{L})$ and aniline $(0.05 \mathrm{~mol} / \mathrm{L})$. Similar to the profiles of the CV curves for the polymerization of
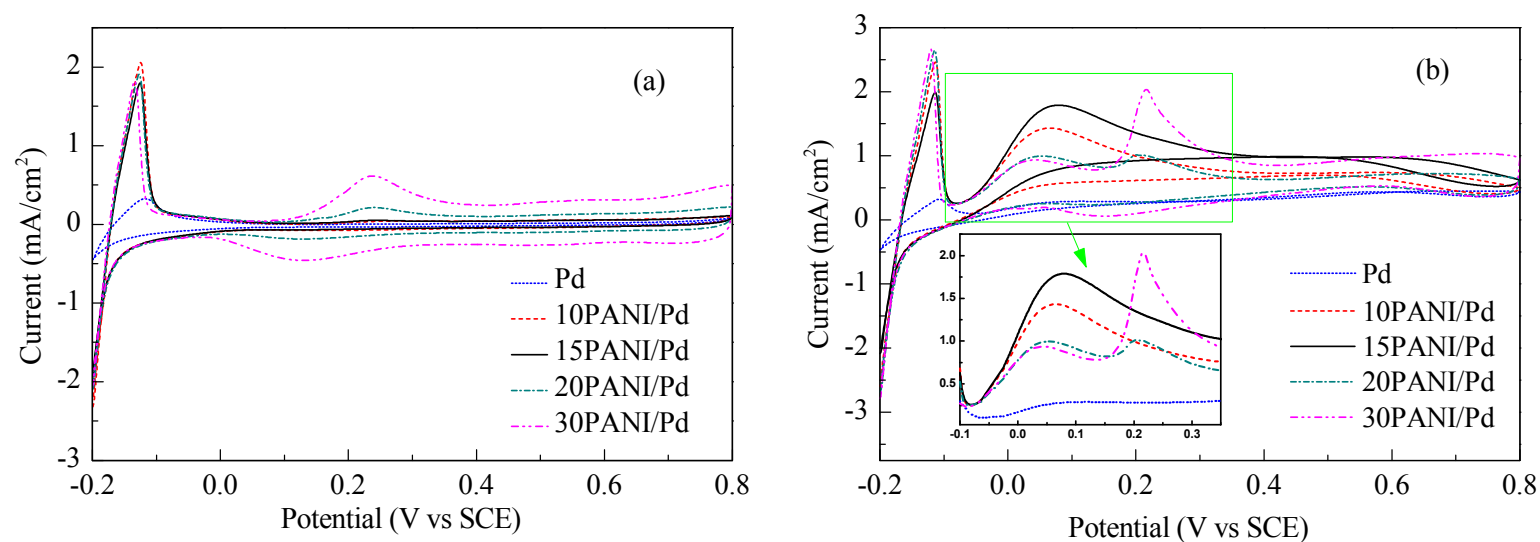

Fig. 5. Cyclic voltammograms of the $n \mathrm{PANI} / \mathrm{Pd}$ catalysts in $\mathrm{H}_{2} \mathrm{SO}_{4}(0.5 \mathrm{~mol} / \mathrm{L})$ (a) and $\mathrm{H}_{2} \mathrm{SO}_{4}(0.5 \mathrm{~mol} / \mathrm{L})+\mathrm{HCOOH}(2.0 \mathrm{~mol} / \mathrm{L})(\mathrm{b})$. The inset in (b) shows the enlarged version of the corresponding positive-going cyclic voltammograms. The CV curves of the pure Pd catalyst without the PANI as the substrate are also included for comparison (scan rate: $50 \mathrm{mV} / \mathrm{s}$ ). 
Table 1

Electrochemical parameters and activity for MOR of Pd $(0.05 \mathrm{~V})$ in $n \mathrm{PANI} / \mathrm{Pd}$ and $\mathrm{Pd} / \mathrm{C} / n \mathrm{PANI}$ catalysts.

\begin{tabular}{lcccc}
\hline Catalyst & $\begin{array}{c}\text { EAS } \\
\left(\mathrm{m}^{2} / \mathrm{g}\right)\end{array}$ & $\begin{array}{c}\text { Mass of Pd on } \\
\text { electrode }(\mu \mathrm{g})\end{array}$ & $\begin{array}{c}\text { MSA } \\
(\mathrm{A} / \mathrm{mg})\end{array}$ & $\begin{array}{c}\text { IA } \\
\left(\mathrm{A} / \mathrm{m}^{2}\right)\end{array}$ \\
\hline 10PANI/Pd & - & 1.59 & 0.177 & - \\
15PANI/Pd & - & 1.63 & 0.209 & - \\
20PANI/Pd & - & 1.71 & 0.117 & - \\
30PANI/Pd & - & 1.80 & 0.104 & - \\
Pd & - & 1.92 & 0.028 & - \\
Pd/C/5PANI & 43.0 & 10 & 0.085 & 1.97 \\
Pd/C/10PANI & 39.2 & 10 & 0.112 & 2.85 \\
Pd/C/20PANI & 38.1 & 10 & 0.135 & 3.55 \\
Pd/C/30PANI & 36.5 & 10 & 0.088 & 2.41 \\
Pd/C/40PANI & 33.3 & 10 & 0.035 & 1.05 \\
Pd/C & 56.0 & 10 & 0.059 & 1.06 \\
\hline
\end{tabular}

EAS: electrochemically active surface area. MSA: mass-specific activity. IA: intrinsic activity.

aniline on a glassy carbon electrode, three couples of peaks corresponding to the redox process of PANI were observed. In addition, pronounced peaks associated with hydrogen adsorption/desorption on the Pd catalyst were also detected in the low potential side of the CV curves. Fig. 6(b) shows the comparison of the $\mathrm{CV}$ curves of $\mathrm{Pd} / \mathrm{C} / n \mathrm{PANI}$ catalysts in $\mathrm{H}_{2} \mathrm{SO}_{4}(0.5$ mol/L) $(n=0-40)$. Increasing the cycle numbers of PANI polymerization showed a slight decrease in the intensity of hydrogen adsorption/desorption peaks, which may be because of the partial overlapping of the PANI networks on the surface of Pd NPs. Because the decrease in the intensity of hydrogen adsorption/desorption peaks is not pronounced, most of the PANI network may be embedded with Pd NPs, which leads to a close proximity between PANI fiber and Pd NPs and enables a promoting effect of PANI on Pd catalysts.

Fig. 7 shows the positive-going FAOR CV curves of $\mathrm{Pd} / \mathrm{C} / n \mathrm{PANI}$ catalysts. The $\mathrm{Pd} / \mathrm{C} / n \mathrm{PANI}$ peaks at around $0.10 \mathrm{~V}$ were attributed to the oxidation of formic acid, which were more negative than that of the $\mathrm{Pd} / \mathrm{C}$ catalyst $(0.18 \mathrm{~V})$. In addition, most of the oxidation current density of the Pd/C/nPANI catalysts show an increase compared with that of the $\mathrm{Pd} / \mathrm{C}$ catalyst, showing a promoting effect of PANI to Pd for FAOR. The $\mathrm{Pd} / \mathrm{C} / n \mathrm{PANI}$ catalysts retained a volcano-shape depend-

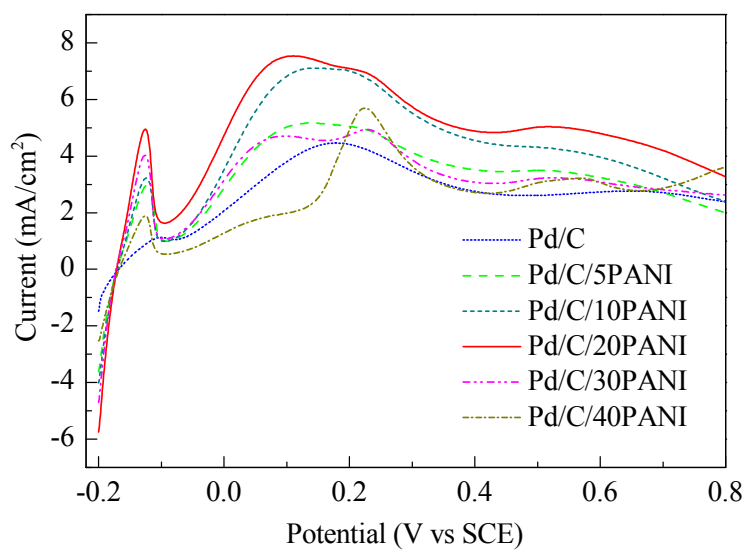

Fig. 7. Cyclic voltammograms of the $\mathrm{Pd} / \mathrm{C} / n \mathrm{PANI}$ catalysts in $\mathrm{H}_{2} \mathrm{SO}_{4}(0.5$ $\mathrm{mol} / \mathrm{L})+\mathrm{HCOOH}(2.0 \mathrm{~mol} / \mathrm{L})$.

ence between the MSA of Pd and the cycle numbers of PANI polymerization as shown in Table 1 . Increasing the cycle numbers from 5 to 10 and then to 20 increased the MSA of Pd (at $0.05 \mathrm{~V}$ ) from 0.085 to 0.112 and then to $0.135 \mathrm{~A} / \mathrm{mg}$, respectively, and further increases to 30 and 40 cycles decreased the current density of FAOR. For the Pd/C/40PANI catalyst, the signal corresponding to the FAOR was difficult to detect, and at the same time, the peak at around $0.22 \mathrm{~V}$ corresponding to the redox process of PANI became pronounced, indicating that the Pd NPs were almost completely covered by PANI. Among the $\mathrm{Pd} / \mathrm{C} / n \mathrm{PANI}$ catalysts, $\mathrm{Pd} / \mathrm{C} / 20 \mathrm{PANI}$ showed the highest MSA for FAOR at $0.135 \mathrm{~A} / \mathrm{mg}$, which was 2.3 times that of the commercial $\mathrm{Pd} / \mathrm{C}$ catalyst at $0.059 \mathrm{~A} / \mathrm{mg}$. These data indicated that PANI shows a significant promoting effect of Pd for the FAOR, which is similar to the results of the $n \mathrm{PANI} / \mathrm{Pd}$ catalysts described above. This enhanced performance of $\mathrm{Pd}$ may be closely related to the change in the electronic structure of $\mathrm{Pd}$ in the presence of PANI.

To identify the change in electronic properties of Pd catalysts, XPS was employed. Fig. 8 shows the XPS spectra of the 15PANI/Pd and Pd/C/20PANI catalysts. Results of the corresponding reference catalysts included the deposited Pd without PANI and commercial Pd/C after potential cycling from -0.2 to
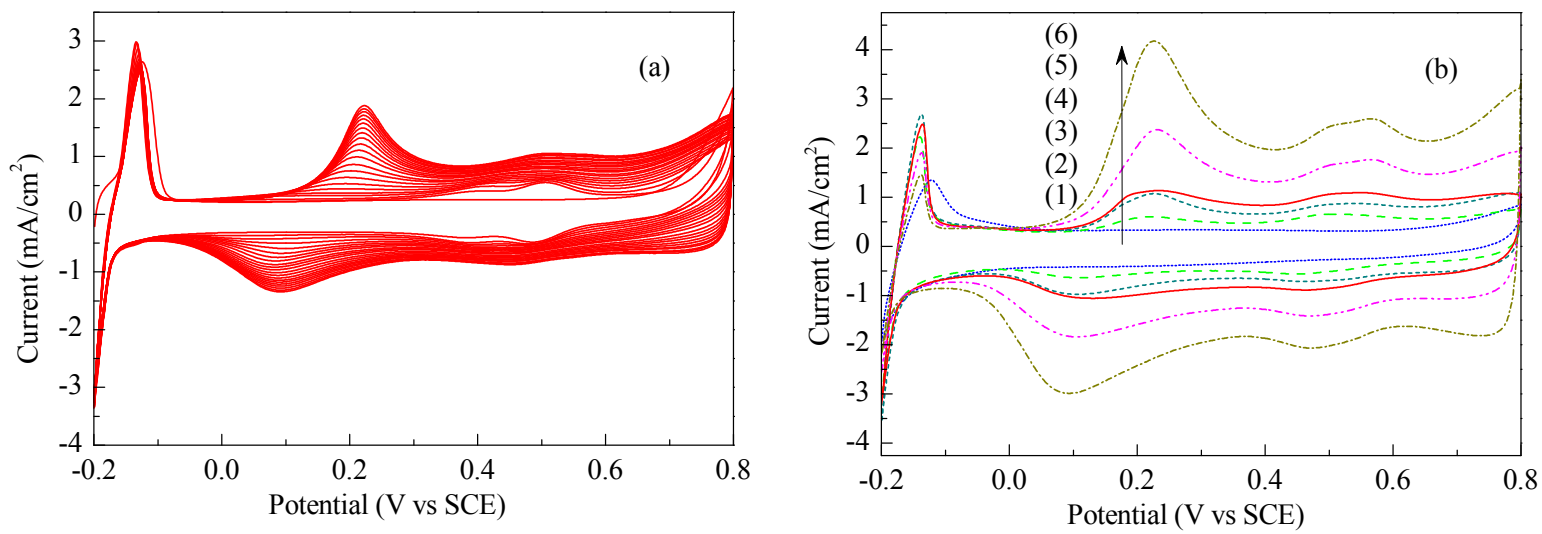

Fig. 6. (a) Successive 20 potential cycles in the course of electrochemical polymerization of aniline in $\mathrm{H}_{2} \mathrm{SO}_{4}(0.5 \mathrm{~mol} / \mathrm{L})+$ aniline $(0.05 \mathrm{~mol} / \mathrm{L})$ on

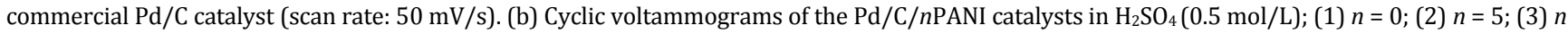
= 10; (4) $n=20$; (5) $n=30$; (6) $n=40$. 


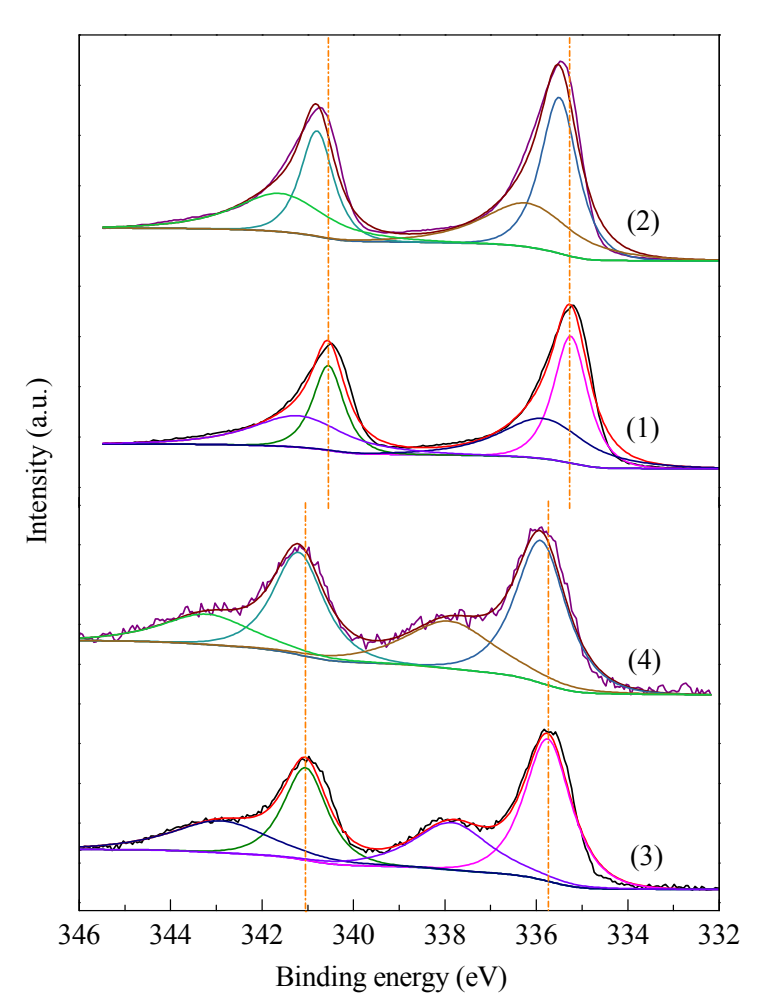

Fig. 8. Pd $3 d$ XPS spectra of the deposited Pd sample without PANI as the substrate (1), 15PANI/Pd (2), commercial Pd/C (3) and $\mathrm{Pd} / \mathrm{C} / 20 \mathrm{PANI}$ (4) samples. Before the XPS measurement, commercial $\mathrm{Pd} / \mathrm{C}$ sample was subjected to the potential cycling in $\mathrm{H}_{2} \mathrm{SO}_{4}(0.5 \mathrm{~mol} / \mathrm{L})$ between -0.2 and $0.9 \mathrm{~V}$ to ensure similar oxidation state with the $\mathrm{Pd} / \mathrm{C} / 20 \mathrm{PANI}$ sample.

$0.9 \mathrm{~V}$. The vertical dashed lines refer to the binding energy (BE) positions for the reference Pd catalysts without PANI. For the 15PANI/Pd catalyst, the Pd $3 d$ signals can be deconvoluted into two doublets. The intense doublet at $\mathrm{BE}=335.5$ and $340.8 \mathrm{eV}$ was characteristic of $\mathrm{Pd}(0)$, and another doublet $(\mathrm{BE}=336.4$ and $341.7 \mathrm{eV}$ ) indicated Pd(II). Fig. 8 shows that the BE positions of $\mathrm{Pd}(0)$ for the 15PANI/Pd catalyst shifted positively by $\sim 0.3 \mathrm{eV}$ compared with those of the Pd catalyst (BE $=335.2$ and $340.5 \mathrm{eV}$ ), suggesting that there is electron transfer from Pd to PANI, and Pd is in an electron deficiency state. Similar results were also observed for the $\mathrm{Pd} / \mathrm{C} / 20 \mathrm{PANI}$ and $\mathrm{Pd} / \mathrm{C}$ catalysts. The electron delocalization between the Pd NPs and PANI alters the electronic structure of $\mathrm{Pd}$, resulting in an improved catalytic activity of Pd for FAOR [33].

CO stripping voltammograms were used to evaluate the CO tolerance and electrochemically active surface areas (EAS) of Pd. Because the electrodeposited quantity of Pd on the electrode was low (1.60-1.80 $\mu \mathrm{g}$ ) for the $n \mathrm{PANI} / \mathrm{Pd}$ catalysts, the CO oxidation peaks were overlapped with oxidation peaks of PANI and the CO stripping voltammograms of $n$ PANI/Pd are not shown in this study. Fig. 9 shows representative CO stripping voltammograms of the $\mathrm{Pd} / \mathrm{C} / n \mathrm{PANI}$ catalysts coated on the electrodes. The voltammetry of the pre-adsorbed $\mathrm{CO}$ was carried out in $\mathrm{H}_{2} \mathrm{SO}_{4}(0.5 \mathrm{~mol} / \mathrm{L})$ for $15 \mathrm{~min}$. Results for the corresponding reference Pd catalysts are also shown for comparison. The anodic peaks at around 0.23 and $0.49 \mathrm{~V}$ were associated with the oxidation of PANI, and the pronounced peaks

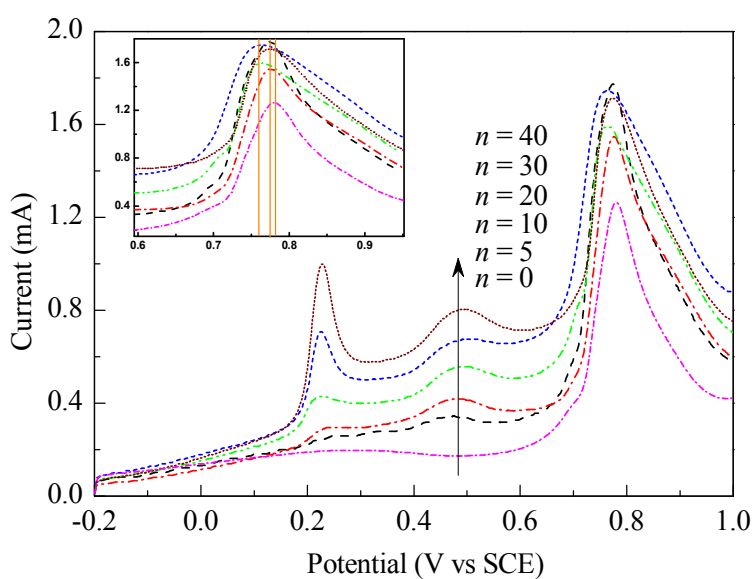

Fig. 9. CO stripping voltammograms of $\mathrm{Pd} / \mathrm{C} / n \mathrm{PANI}$ catalysts in $\mathrm{H}_{2} \mathrm{SO}_{4}$ $(0.5 \mathrm{~mol} / \mathrm{L})$. The inset shows the enlarged version of the $\mathrm{CO}$ oxidation peaks.

at around $0.78 \mathrm{~V}$ were from the oxidative removal of $\mathrm{CO}$ monolayer on the electrode. Profiles of $\mathrm{CO}$ oxidation on the $\mathrm{Pd} / \mathrm{C} / n \mathrm{PANI}$ catalysts were similar to those on the $\mathrm{Pd} / \mathrm{C}$ catalyst, whereas the onset and peak potentials showed a slight difference. $\mathrm{Pd} / \mathrm{C} / 20 \mathrm{PANI}$ and $\mathrm{Pd} / \mathrm{C} / 30 \mathrm{PANI}$ catalysts showed the most $\mathrm{CO}$ oxidation negative peak potential $(0.76 \mathrm{~V})$, which was $\sim 20 \mathrm{mV}$ more negative than those of the other Pd/C/nPANI and $\mathrm{Pd} / \mathrm{C}$ catalysts. These observations suggest that the presence of PANI improves the CO tolerance of $\mathrm{Pd}$, and interaction between Pd and PANI was crucial for this improvement. In addition, the EAS of Pd can be calculated by integrating the $\mathrm{CO}$ stripping peaks, followed by subtracting the area arising from the double layer charging and oxidation formation, which was measured from the second cycle after the oxidative removal of CO monolayer (Table 1). For the $\mathrm{Pd} / \mathrm{C} / n$ PANI catalysts, all of the EAS values of Pd were lower than that of the $\mathrm{Pd} / \mathrm{C}$ catalyst $\left(56.0 \mathrm{~m}^{2} / \mathrm{g}\right.$ ) because of the PANI coating. Increasing electropolymerization cycles of PANI gradually decreased the EAS of $\mathrm{Pd}$ in the $\mathrm{Pd} / \mathrm{C} / n \mathrm{PANI}$ catalysts from $43.0 \mathrm{~m}^{2} / \mathrm{g}$ at $n=5$ to 39.2 $\mathrm{m}^{2} / \mathrm{g}$ and $36.5 \mathrm{~m}^{2} / \mathrm{g}$ at $n=10$ and 30 , respectively. When the electropolymerization cycles of PANI increased to 40, the EAS data decreased to $33.3 \mathrm{~m}^{2} / \mathrm{g}$. The intrinsic activity (IA) of Pd in the $\mathrm{Pd} / \mathrm{C} / n \mathrm{PANI}$ catalysts was obtained by normalizing the current density of FAOR to the EAS of Pd. Except for $\mathrm{Pd} / \mathrm{C} / 40 \mathrm{PANI}$, all of the $\mathrm{Pd} / \mathrm{C} / n \mathrm{PANI}$ catalysts showed improved IA compared with that of the commercial Pd/C catalyst, indicating that PANI can act as a promoter to Pd for FAOR. Among the $\mathrm{Pd} / \mathrm{C} / n$ PANI catalysts, Pd/C/20PANI showed the highest IA, which was 3.3 times that of the $\mathrm{Pd} / \mathrm{C}$ catalyst. The enhanced catalytic activity may be associated with the proximity of Pd and PANI and the change in the electronic structure of Pd.

\subsection{Stability of the $n P A N I / P d$ and $P d / C / n P A N I$ catalysts}

Chronoamperometric analyses were carried out to evaluate the activity and stability of 15PANI/Pd, Pd/C/20PANI, and the reference $\mathrm{Pd}$ and $\mathrm{Pd} / \mathrm{C}$ catalysts. Fig. 10 shows the chronoamperograms (at $0 \mathrm{~V}$ ) of the catalysts in $\mathrm{H}_{2} \mathrm{SO}_{4}(0.5 \mathrm{~mol} / \mathrm{L})$ and 


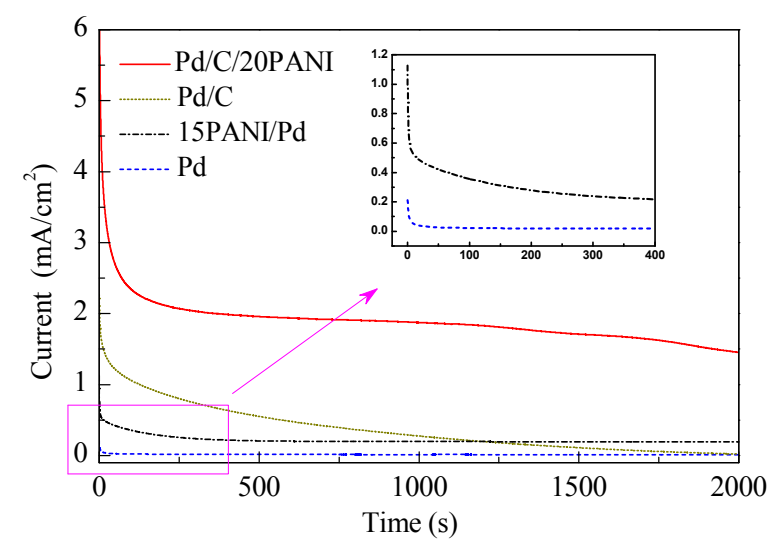

Fig. 10. Chronoamperometry curves of the $\mathrm{Pd} / \mathrm{C} / 20 \mathrm{PANI}, \mathrm{Pd} / \mathrm{C}$, 15PANI/Pd, and electrodeposited Pd catalysts in $\mathrm{H}_{2} \mathrm{SO}_{4}(0.5 \mathrm{~mol} / \mathrm{L})+$ $\mathrm{HCOOH}(2.0 \mathrm{~mol} / \mathrm{L})$ under the potential of $0 \mathrm{~V}$. The inset shows the enlarged version of the chronoamperometry curves of 15PANI/Pd and electrodeposited Pd catalysts.

$\mathrm{HCOOH}(2.0 \mathrm{~mol} / \mathrm{L})$ solution. Because the loadings of Pd on the electrode for the Pd/C/20PANI and Pd/C catalysts were higher than those for the 15PANI/Pd and Pd catalysts, the initial oxidation current density was also higher. For the Pd/C/20PANI catalyst, both the initial and the steady-state oxidation current density were higher than those for the $\mathrm{Pd} / \mathrm{C}$ catalyst, the current density on $\mathrm{Pd} / \mathrm{C} / 20 \mathrm{PANI}$ catalyst at $2000 \mathrm{~s}\left(1.49 \mathrm{~mA} / \mathrm{cm}^{2}\right)$ was around 50 times that on the $\mathrm{Pd} / \mathrm{C}$ catalyst $\left(0.03 \mathrm{~mA} / \mathrm{cm}^{2}\right)$. Similar results were also found for the 15PANI/Pd and Pd catalysts, where the current densities at $2000 \mathrm{~s}$ were 0.22 and $0.02 \mathrm{~mA} / \mathrm{cm}^{2}$ (inset of Fig. 10), respectively. The MSA of 15PANI/Pd (0.027 A/mg) was 12.9 times that of the Pd catalyst $(0.002 \mathrm{~A} / \mathrm{mg})$. These data suggest that the presence of PANI in Pd catalysts enhances the catalytic activity and stability for FAOR. These results are consistent with the above voltammetric results. The improved electronic conductivity of the compo- site catalysts because of the presence of PANI may be one of the reasons for the enhanced catalytic properties of Pd [25], and comprehensive investigations need to be carried out in future studies.

\section{Conclusions}

This study reports two PANI-promoted Pd catalysts for FAOR. PANI alone has no catalytic property for FAOR. However, PANI shows significant promoting effects on Pd catalysts. These promoting effects are strongly dependent on the numbers of potential cycles for the polymerization of PANI. For both the $n \mathrm{PANI} / \mathrm{Pd}$ and $\mathrm{Pd} / \mathrm{C} / n \mathrm{PANI}$ catalysts, the current density of FAOR shows distinct enhancements compared with those of the Pd reference catalysts. The highest current density of FAOR on the $n \mathrm{PANI} / \mathrm{Pd}$ and $\mathrm{Pd} / \mathrm{C} / n \mathrm{PANI}$ catalysts are for $15 \mathrm{PANI} / \mathrm{Pd}$ and $\mathrm{Pd} / \mathrm{C} / 20 \mathrm{PANI}$, respectively. These findings show important application for the design and preparation of electrocatalysts for the FAOR and the development of DFAFCs and other catalytic technology.

\section{References}

[1] Hoffmann P. Tomorrow's Energy: Hydrogen, Fuel Cells, and the Prospects for a Cleaner Planet. MIT Press, 2012

[2] Zhang H W, Shen P K. Chem Rev, 2012, 112: 2780

[3] Yan Z Y, Li B, Yang D J, Ma J X. Chin J Catal (严泽宇, 李冰, 杨代军, 马建新. 催化学报), 2013, 34: 1471

[4] Aricò A S, Srinivasan S, Antonucci V. Fuel Cells, 2001, 1: 133

[5] Song S Q, Tsiakaras P. Appl Catal B, 2006, 63: 187

[6] Luo Y L, Liang Z X, Liao S J. Chin J Catal (罗远来, 梁振兴, 廖世军. 催化学报), 2010, 31: 141

[7] Yu X W, Pickup P G.J Power Sources, 2008, 182: 124

[8] Mazumder V, Chi M F, Mankin M N, Liu Y, Metin Ö, Sun D H, More K L, Sun S H. Nano Lett, 2012, 12: 1102

[9] Jiang K, Cai W B. Appl Catal B, 2014, 147: 185

\section{Graphical Abstract}

Chin. J. Catal., 2015, 36: 943-951 doi: 10.1016/S1872-2067(15)60863-4

\section{Promoting effect of polyaniline on Pd catalysts for the formic acid electrooxidation reaction}

Xianbin Ma, Yuanyuan Feng*, Yang Li, Yunshi Han, Guoping Lu, Haifang Yang, Desheng Kong Qufu Normal University
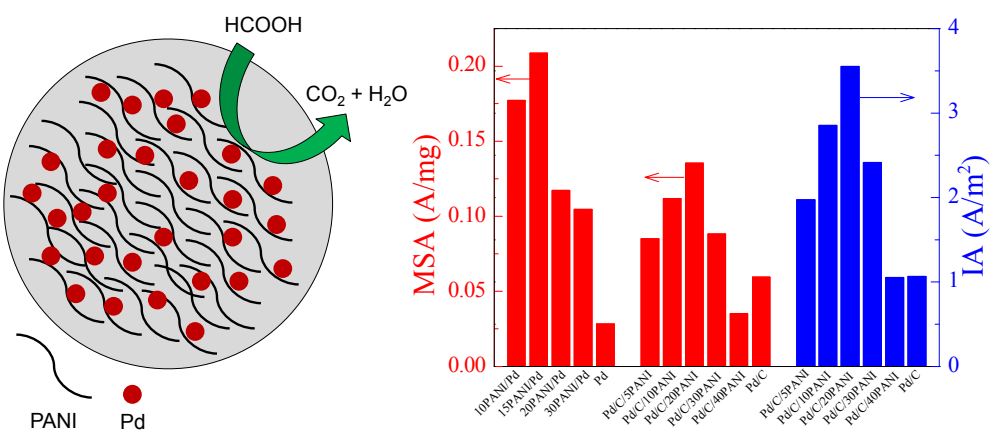

For both $n \mathrm{PANI} / \mathrm{Pd}$ and Pd/C/nPANI catalysts, polyaniline (PANI) shows significant promoting effect on Pd catalyst toward formic acid electrooxidation reaction. 
[10] Chen J W, Li Y J, Liu S R, Wang G, Tian J, Jiang C P, Zhu S F, Wang R L. Appl Surf Sci, 2013, 287: 457

[11] Wang J Y, Kang Y Y, Yang H, Cai W B. J Phys Chem C, 2009, 113: 8366

[12] Masud J, Alam M T, Miah Md R, Okajima T, Ohsaka T. Electrochem Commun, 2011, 13: 86

[13] Hu C G, Cao Y X, Yang L, Bai Z Y, Guo Y M, Wang K, Xu P L, Zhou J G. Appl Surf Sci, 2011, 257: 7968

[14] Sun Z P, Zhang X G, Tong H, Xue R L, Liang Y Y, Li H L. Appl Surf Sci, 2009, 256: 33

[15] Chen S G, Wei Z D, Qi X Q, Dong L C, Guo Y G, Wan L J, Shao Z G, Li L. J Am Chem Soc, 2012, 134: 13252

[16] Pandey R K, Lakshminarayanan V. J Phys Chem C, 2009, 113: 21596

[17] Ding K G, Jia H T, Wei S Y, Guo Z H. Ind Eng Chem Res, 2011, 50: 7077

[18] Ríos E, Abarca S, Daccarett P, Hguyen Cong N, Martel D, Marco J F, Gancedo J R, Gautier J L. Int J Hydrogen Energy, 2008, 33: 4945

[19] Dong B, Song D F, Zheng L Q Xu J K, Li N.J Electroanal Chem, 2009, 633: 63

[20] Selvaraj V, Alagar M, Hamerton I. Appl Catal B, 2007, 73: 172
[21] Zhou W Q, Xu J K, Du Y K, Yang P. Int J Hydrogen Energy, 2011, 36: 1903

[22] Feng Y Y, Yin Q Y, Lu G P, Yang H F, Zhu X, Kong D S, You J M. J Power Sources, 2014, 272: 606

[23] Feng Y Y, Liu Z H, Xu Y, Wang P, Wang W H, Kong D S. J Power Sources, 2013, 232: 99

[24] Wang L C, Xu L Q, Sun C, Qian Y T. J Mater Chem, 2009, 19: 1989

[25] Yaldagard M, Jahanshahi M, Seghatoleslami N. Appl Surf Sci, 2014, 317: 496

[26] Yang Y, Diao M H, Gao M M, Sun X F, Liu X W, Zhang G H, Qi Z, Wang S G. Electrochim Acta, 2014, 132: 496

[27] He B L, Tang Q W, Wang M, Chen H Y, Yuan S S. ACS Appl Mater Interface, 2014, 6: 8230

[28] Niu L, Li Q H, Wei F H, Chen X, Wang H. Synth Met, 2003, 139: 271

[29] Wang Z, Zhu Z Z, Shi J, Li H L. Appl Surf Sci, 2007, 253: 8811

[30] Pan W, Zhang X K, Ma H Y, Zhang J T. J Phys Chem C, 2008, 112: 2456

[31] Birry L, Lasia A. Electrochim Acta, 2006, 51: 3356

[32] Zhang J T, Huang M H, Ma H Y, Tian F, Pan W, Chen S H. Electrochem Commun, 2007, 9: 1298

[33] Zhou W J, Lee J Y.J Phys Chem C, 2008, 112: 3789

\title{
聚苯胺对钯催化甲酸电氧化反应的促进作用
}

\author{
马先斌, 冯媛媛 ${ }^{*}$, 李扬, 韩运石, 鹿国萍, 杨海芳, 孔德生
} 曲阜师范大学化学与化工学院, 山东省生命有机分析重点实验室, 山东曲阜273165

摘要: 钯基纳米材料是甲酸电氧化反应的优良催化剂. 本工作制备了两个系列钯基催化剂, 并考察了聚苯胺对钯上甲酸电氧化反 应的助催化作用. 一种是以聚苯胺为基底, 在其表面电沉积钯纳米粒子, 制得 $n \mathrm{PANI} / \mathrm{Pd}$ 催化剂( $n$ 表示聚合苯胺的循环数); 另一种 是直接在商业 $\mathrm{Pd} / \mathrm{C}$ 催化剂表面电聚合苯胺, 制得 $\mathrm{Pd} / \mathrm{C} / n \mathrm{PANI}$ 催化剂. 结果显示, 聚苯胺单独存在时对甲酸电氧化反应没有催化活 性, 但其可对钯上甲酸电氧化反应呈现明显的促进作用, 且促进作用与聚苯胺的厚度(聚合循环数)密切相关. 在两个系列催化剂 中, $15 \mathrm{PANI} / \mathrm{Pd}$ 和Pd/C/20PANI显示出最高的催化性能. $15 \mathrm{PANI} / \mathrm{Pd}$ 中钯的质量比催化活性是纯钯催化剂的7.5倍; $\mathrm{Pd} / \mathrm{C} / 20 \mathrm{PANI}$ 钯的质量比催化活性和本征催化活性分别是商业 $\mathrm{Pd} / \mathrm{C}$ 催化剂的 2.3 和 3.3 倍. 钯催化性能的提升与聚苯胺和钯纳米粒子间的电子 效应有关.

关键词: 钯; 聚苯胺; 电催化; 甲酸电氧化反应

收稿日期: 2015-01-04. 接受日期: 2015-04-14. 出版日期: 2015-07-20.

*通讯联系人. 电话: (0537)4458301; 电子信箱：yfeng@mail.tsinghua.edu.cn

基金来源：国家自然科学基金(21403125); 山东省优秀中青年科学家科研奖励基金(BS2011NJ009).

本文的英文电子版由Elsevier出版社在ScienceDirect上出版(http://www.sciencedirect.com/science/journal/18722067). 